Article

\title{
Exploring the Interplay between CAD and FreeFem++ as an Energy Decision-Making Tool for Architectural Design
}

\author{
Juan Rojas-Fernández ${ }^{1}$, Carmen Galán-Marín ${ }^{1, *}$,, Carlos Rivera-Gómez ${ }^{1}$ and \\ Enrique D. Fernández-Nieto ${ }^{2}$ \\ 1 Department of Building Construction, E.T.S. Arquitectura, Universidad de Sevilla, 41012 Seville, Spain; \\ jmrojas@us.es (J.R.-F.); crivera@us.es (C.R.-G.) \\ 2 Department of Applied Mathematics, E.T.S. Arquitectura, Universidad de Sevilla, 41012 Seville, Spain; \\ edofer@us.es \\ * Correspondence: cgalan@us.es; Tel.: +34-954-55-65-91
}

Received: 17 September 2018; Accepted: 3 October 2018; Published: 7 October 2018

\begin{abstract}
The energy modelling software tools commonly used for architectural purposes do not allow a straightforward real-time implementation within the architectural design programs. In addition, the surrounding exterior spaces of the building, including the inner courtyards, hardly present a specific treatment distinguishing these spaces from the general external temperature in the thermal simulations. This is a clear disadvantage when it comes to streamlining the design process in relation to the whole-building energy optimization. In this context, the present study aims to demonstrate the advantages of the FreeFem++ open source program for performing simulations in architectural environments. These simulations include microclimate tests that describe the interactions between a building architecture and its local exterior. The great potential of this mathematical tool can be realized through its complete system integration within CAD (Computer-Aided Design) software such as SketchUp or AutoCAD. In order to establish the suitability of FreeFem++ for the performance of simulations, the most widely employed energy simulation tools able to consider a proposed architectural geometry in a specific environment are compared. On the basis of this analysis, it can be concluded that FreeFem++ is the only program displaying the best features for the thermal performance simulation of these specific outdoor spaces, excluding the currently unavailable easy interaction with architectural drawing programs. The main contribution of this research is, in fact, the enhancement of FreeFem++ usability by proposing a simple intuitive method for the creation of building geometries and their respective meshing (pre-processing). FreeFem++ is also considered a tool for data analysis (post-processing) able to help engineers and architects with building energy-efficiency-related tasks.
\end{abstract}

Keywords: energy efficiency; energy modelling software; architectural design tool; outdoor space; courtyard; FreeFem++; Computer-Aided Design (CAD)

\section{Introduction}

Energy saving is of increasing concern to the community. The energy efficiency of buildings and cities is directly related to the preservation of energy resources and the buildings' or cities' effects on climate change due to the use of conventional energy sources. The current need for energy efficiency has led to the development of increasingly precise tools for energy modelling in buildings. Subsequently, over the last decade, there has been an enormous growth in the quantity of simulation programs and in their energy modelling capabilities. These improved tools have been progressively considering 
a greater number of variables and data that scientists have come to deal with. Undeniably, this has been triggered to a large extent by the growth in speed and memory capacity of electronic computers. Numerical simulations now enable us to tackle complex physical problems like never before [1]. Such problems involve the understanding and calculation of atmospheric behaviours. Their complexity derives from the interaction of factors ranging from fluid mechanics to thermodynamics showing nonlinear behaviours [2]. The interaction between buildings and atmospheric phenomena produces microclimates in the nearby environment, characterised by air properties that differ from the outside average. These properties depend, among other factors, on the buildings' architecture. This is the case for monitored courtyards in hot and temperate climates [3], where air temperatures inside the courtyard are significantly lower than on the exterior during the summer. The physical complexity of the phenomena and their strong interaction with formal design has prevented their controlled use in architecture until now. Previous research demonstrates that the architectural design and its materialization is a key factor in determining how the air within these microclimates behaves in spaces such as courtyards which can cool the exterior air, especially during the summer [4]. This notion should encourage architects to focus their designs on the creation, optimization, and best use of microclimates. Consequently, this stimulates performance-driven architectural design from the beginning, considering energy aspects besides the traditional factors of form and space [5-7].

In recent years, many governments have been promoting the use of BIM (Building Information Modelling) as a means of facilitating collaboration and improving delivery efficiency and project quality [8]. Software suppliers have flooded the market with numerous BIM software packages dealing with different types of construction information throughout those years. This has led to end-users facing significant challenges as to which software systems to use, in which type of construction domains/activities, and how to effectively use the chosen software packages(s) $[9,10]$. Although the current plug-ins allow energy simulation to be integrated from the beginning of the design phase through the BIM model [11], the software package used is always located among the energy modelling systems commonly used. Such modelling tools, as will be discussed below, do not provide an appropriate solution to the level of thermal simulation accuracy needed to model small-sized outdoor spaces such as inner courtyards [12].

The main research aim of this paper is to enable integrated software that would significantly improve building design from the perspective of energy efficiency. Accordingly, the present work confronts the problem by means of collaboration between mathematicians, engineers, and architects. This makes more accessible the potentiality of the free code FreeFem++ mathematical tool for the development of numerical simulations of these microclimates by proposing its integration with the proper architecture and engineering software. Therefore, to confront the problem, its use and integration with architectural software $\left(\right.$ AutoCAD $^{\circledR}$, SketchUp $^{\circledR}$, FreeFem++, and ParaView) will be proposed.

\section{Energy Analysis Simulation Tools}

As a result of the analysis and calculation complexity, and the need to manage equations defining the behavior of the fluid mechanics coupled with those equations describing thermodynamical behaviors, the following 3D numerical model programmes are based on CFD (Computational Fluid Dynamics) [13]. This branch of fluid mechanics is based on numerical methods and algorithms used to solve and analyze problems involving fluid flows. The programs most commonly employed to solve engineering and mathematical physics problems related to heat transfer and fluid flow are described below.

\subsection{ANSYS Fluent}

ANSYS Fluent is one of the most widely used tools in engineering based on CFD (Computational Fluid Dynamics) for finite elements. Originally conceived to model flows (mechanical problems in fluid dynamics), it is also used today for calculating heat transfers and reactions for industrial 
applications [14], which means it can be used for energy and climate simulations. Among its strengths are its capacity for importing files from the main CAD platforms, its calculating power, and its good visualization of results. However, it is not widely used in architecture due to the high time and effort costs required to apply it to architectural problems. Another major drawback for researchers is that the code is inaccessible; this makes it difficult to see how simulation calculations are reached, hindering understanding of the mathematical description of the process and, therefore, its integral knowledge.

\subsection{DesignBuilder}

DesignBuilder specializes in energy and environmental simulations for buildings, and it was designed specifically for architecture and the engineering involved in installations related to it [15]. The Pro version includes a CFD module that can simulate air flows and temperature distributions in spaces both inside and outside buildings using algorithms equivalent to the CFD programs in common use (such as Simpler). One of the advantages of this program is its simplicity when handling these algorithms, enabling the user to configure the geometry and conditions in the environment with precision. The program achieves this by providing options for easy configuring of conditions such as surface temperatures, heat flows, and air volumes, based on the results of a simulation with the EnergyPlus software developed by the U.S. Department of Energy, which we will analyze later. The program offers simplicity and usability, allowing the user to import files from the CAD and BIM platforms. Usability is one of this program's big pluses but, sadly, as in nearly all the cases studied, it is not an open source tool. Besides this, it does not take into account different outer temperatures for different transition spaces such as in the case of inner courtyards. DesignBuilder considers a single homogenous external reference temperature around the building for the calculation of the overall energy balance of the building and heat balance with the environment in any climate. In fact, in the DesignBuilder manual, courtyards are specifically mentioned (Section 3.2 and 10.4 in the manual) to indicate how to create them and are specified as exterior, not as a different outside zone.

\subsection{Revit Autodesk (Formerly Ecotect Analysis)}

Another program widely used by architects in energy simulation and analysis is Revit Autodesk, formerly called Ecotect Analysis. This tool allows the user to study different energy behaviors in buildings, including analysis of solar radiation, natural lighting, water consumption, and sound propagation [16]. One of the advantages is that the user can import three-dimensional geometries from specific design programs such as AutoCAD, Revit, or SketchUp, as well as from the architect's own design model.

It also includes a study model for exterior urban spaces to pinpoint a building's best orientation for maximum sunlight exposure. However, the program's climate study is inadequate for determining the condition of the specific exterior spaces we want to examine. The Sky View Factor parameters together with the incident and reflected radiation are important aspects of an energy study of these spaces but are insufficient for simulating their behavior in detail. Thermodynamic phenomena like stratification and convection, as well as fluid dynamics such as flow patterns, are also essential, thus making it necessary to carry out a CFD simulation which this program cannot perform. This limitation is due to the fact that Revit focuses more on a building's interior energy conditions than on those of the exterior space [17]. It is not an open source code program, and as previously mentioned, this means that they do not allow us to understand the internal calculation processes of the physical phenomena.

\subsection{SUNtool, Solene, RayMan, URSOS, and GreenCanyon.}

Other programs have been developed by institutional research teams to perform energy behavior calculations from different perspectives. These include SUNtool [18], Solene [19], and RayMan [20], all of which have good graphical interfaces that enable the geometry to be entered intuitively. SUNtool is compatible with the main CAD design software programs such as AutoCAD, ArchiCAD, SketchUp, and Rhino. These energy simulation programs tackle the problem by focusing on radiation calculations 
and their thermal consequences. This simplification is insufficient if the researcher wishes to study the microclimate and the air behavior in specific exterior spaces. Although they are not commercial programs, neither are they open source coded.

This is also the case with other programs such as URSOS [21] and GreenCanyon [2], which are research oriented. Although they can consider more factors than just radiation, including those derived from CFD-based characterizations, they are also closed source. What is more, SUNtool is still not generally available to the public, which hinders scientific debate.

\subsection{EnergyPlus}

An example of a widely used noncommercial open source calculation tool is EnergyPlus which can be downloaded free from the official web page of the U.S. Department of Energy [22]. This program also provides the calculation engine for other commercial programs such as DesignBuilder. It is a wide-reaching program for use by architects, engineers, and researchers that enables energy simulations for buildings which can help optimize the design and reduce water consumption. It models systems of heating, refrigeration, lighting, ventilation, and other energy flows and water usages. To make it easier to use, the web page provides a plugin that allows simulations with EnergyPlus using SketchUp. We have already mentioned how other programs have tried to be compatible with this 3D design tool, and there are two main reasons for this: the basic version is free and is highly intuitive, making it quick and easy to construct any size or volume. Its considerable power and flexibility make EnergyPlus one of the best tools for energy simulations in buildings, but it does not take into account energy simulations for exterior spaces.

\subsection{ENVI-Met 3.1}

Among the calculation tools made specifically to simulate exterior spaces or microclimates of urban spaces is ENVI-met 3.1, which is currently being used by several researchers in this field due to its reliable results [23]. The program was created by Michael Bruse (Institute of Geography, Department of Geoinformatics, Environmental Modeling Group, University of Mainz) to simulate the interaction between surfaces, floors, and air in an urban setting based on fluid dynamic and thermodynamic models [24]. It enables the calculation of various exterior space parameters such as air quality and thermal comfort, for which it only requires the geometry and climate data that can be gathered from any nearby meteorological station. There was also a timely investigation by X. Yang, L. Zhao, M. Bruse, and Q. Meng [25] that links ENVI-met 3.1's capacity to simulate climate conditions in urban spaces with EnergyPlus's ability to provide energy simulations of a building's interior.

The scientific study of the complex microclimate behavior of specific spaces such as patios requires a full understanding of the physical processes involved and the mathematics used to describe these processes, as well as the numerical treatment applied to simulate them. This cannot be done using closed source programs as they block access to the mathematical model on which their calculations are based. Furthermore, ENVI-met does not provide sufficiently accurate simulations of the temperature of small-sized outdoor spaces, as in the case of inner courtyards [12]. Only by using open source programs with free calculation tools can researchers generate a transparent program that enables an understanding of its mathematical processes and the physical phenomena described.

\subsection{FreeFem++}

To carry out numerical simulations, use of the FreeFem++ programming language and free software as a calculation engine is proposed. It is not a program made specifically for studying microclimates; rather it is an open computer language for performing any kind of simulation based on numerical models via the finite element method. In principle, this program is not easy to use beyond research parameters, so the goal of this research is to increase its usability for introducing data into the simulation, or pre-processing, and the subsequent analysis, or post-processing. 
FreeFem++ is especially useful for researchers because it combines considerable calculating power with flexibility and the transparency of its open source code. As a result, it has given rise to an internet community of developers of the program who tend to be researchers working on numerical simulations [26,27]. One of the big advantages of FreeFem++ is that it can be used as a high-level programming language based on $\mathrm{C}++$, enabling combinations of high-level FreeFem++ commands with C++ commands to develop one's own codes. This offers considerable flexibility for developing simulation codes which in many cases cannot be done with commercial codes. In addition, FreeFem++ commands allow compact programming of different methods with finite elements regardless of the study problem, which means that it is highly versatile and eminently suitable for tackling problems involving thermodynamics and fluid mechanics [27].

The software is also often used in research for pre- and post-processing simulations. Nevertheless, suppling geometric data to the models requires the user to write lines of code using the FreeFem++ programming language derived from $\mathrm{C}++$, after which all the lines of the drawing need to be translated into mathematical expressions. Despite its abstract nature, this procedure of entering the geometries is only viable when they are in simple 2D forms (Figure 1). When studying three-dimensional objects, the complexity of the translation of their geometry into lines of FreeFem++ code increases considerably. The method is not totally impossible to execute but professional users more interested in the results than in the processes would find it unfeasible. It focuses far more on the stages of the mathematical construction of the form than on the behavior or physical consequences of the totality of the form, which is what appeals to professionals the most. The geometric data of a hypothetical simple square room with several windows in FreeFem++ requires analytical description of a series of geometric operations such as 3D folding and rotations [28]. The reality of architectural practice often means dealing with geometries that are much more complex. Thus, it is necessary to find a simpler way to enter geometric data in order to focus on the study [29].

Table 1 summarizes the characteristics of the calculation tools studied. This provides a visual comparison of the reach of each program according to whether it simulates exterior spaces (in green), performs CFDs, is free, open source, or if it can interact with the drawing programs typically used in architecture (AutoCAD and/or SketchUp). FreeFem++ is the only program that possesses all these features, except for easy interaction with architectural drawing programs (in red) [30]. Our study develops a method for improving that shortcoming, thus making FreeFem++ an optimal tool for resolving this type of problem.
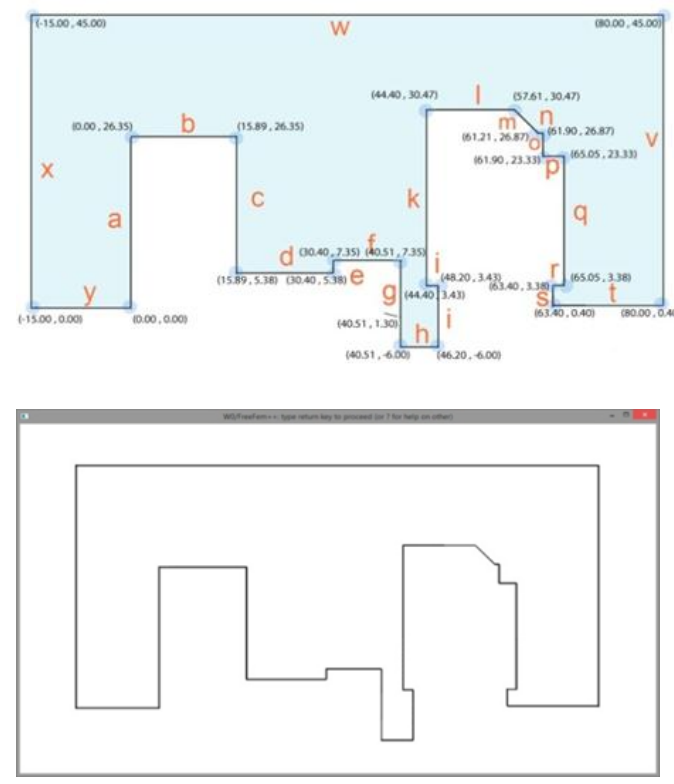

border $I(t=44.40,57.61)\{x=t ; y=30.47$; label $=12 ;\}$; border $m(t=3.6,0)\{x=61.21 \cdot t ; y=26.87+t ;$ label $=13 ;\}$ border $n(t=61.21,61.90)\{x=t ; y=26.87 ;$ label $=14 ;\}$; border $o(t=0,3.54)\{x=61.90 ; y=26.87$-t;label $=15 ;\}$; border $p(t=61.90,65.05)\{x=t ; y=23.33 ;$ label $=16 ;\}$; border $q(t=0,19.85)\{x=65.05 ; y=23.30$-t: label $=17 ;\}$; border $r(t=0,1.65)\{x=65.05-t ; y=3.48 ;$ label $=18 ;\}$; border $s(t=0,3.08)\{x=63.40 ; y=3.48$-t;label $=19 ;\}$; border $\mathrm{t}(\mathrm{t}=63,40,80.00)\{\mathrm{x}=\mathrm{t} ; \mathrm{y}=0.40$; label $=20 ;\}$; border $v(t=0.40,45.00)\{x=80.00 ; y=t$; label $=21 ;\}$; border $w(t=0,95.00)\{x=80-t ; y=45$; label $=22 ;\}$; border $x(t=0,45)\{x=-15 ; y=45-t ;$ label $=23 ;\}$; border $y(t=15,0)\{x=0$-t; $y=0 ;$ label $=24 ;$;

Figure 1. Cont. 


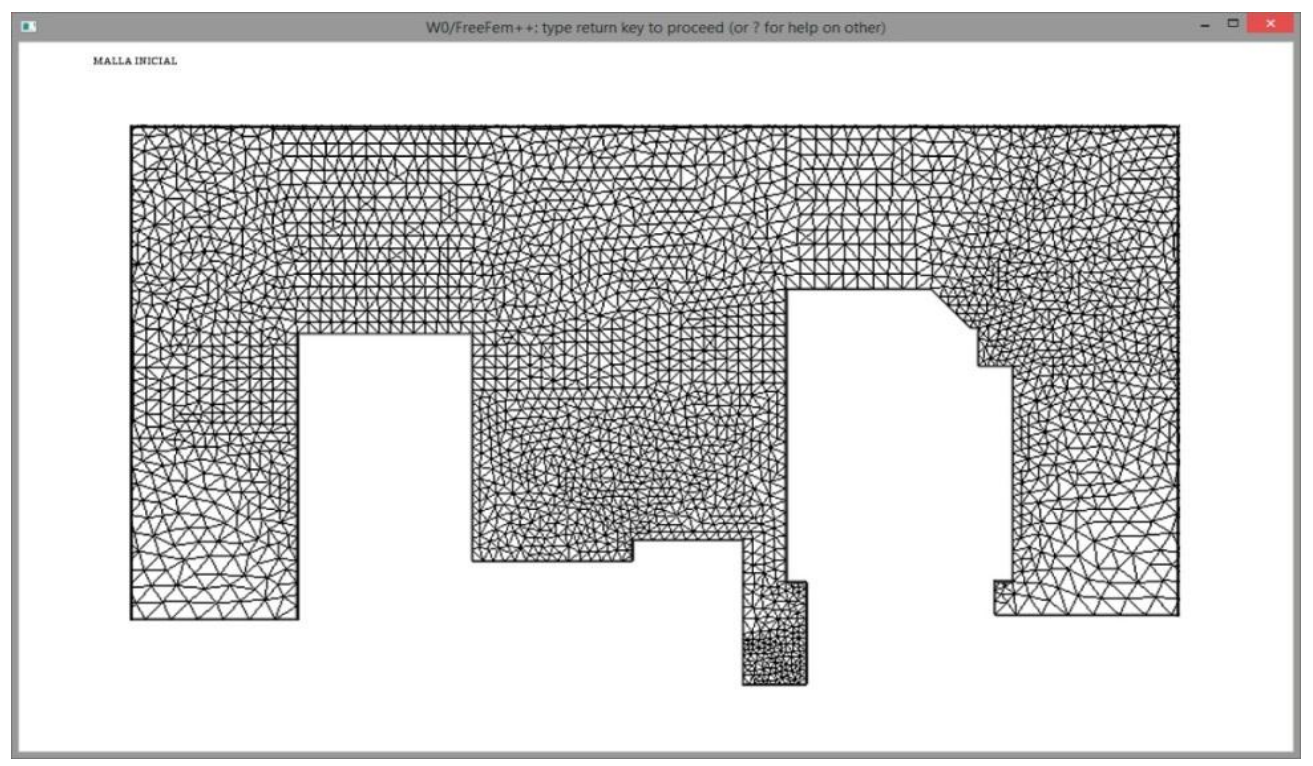

Figure 1. 2D example of building geometry.

Table 1. Summarizing the features of the energy calculation programs.

- fulfilled issue $\boldsymbol{\square}$ pending issue.

\begin{tabular}{|c|c|c|c|c|c|}
\hline Software Analysed & $\begin{array}{l}\text { Outdoor Conditions } \\
\text { Simulations }\end{array}$ & $\begin{array}{l}\text { Simulations } \\
\text { Using CFD }\end{array}$ & $\begin{array}{c}\text { Free } \\
\text { Software }\end{array}$ & $\begin{array}{l}\text { Open } \\
\text { Sauce }\end{array}$ & $\begin{array}{c}\text { AutoCAD/Sketchup } \\
\text { Import }\end{array}$ \\
\hline ANSYS Fluent & - & - & & & $\square$ \\
\hline DesignBuilder & - & - & & & - \\
\hline Revit/Ecotect Analysis & - & & & & - \\
\hline SUNtool & - & & a & & \\
\hline Solene & - & & a & & \\
\hline RayMan & - & & - & & \\
\hline URSUS & - & & - & & \\
\hline GreenCanyon & घ & - & - & & \\
\hline EnergyPlus & & - & - & - & - \\
\hline ENVI-met & - & - & - & & \\
\hline Software using FreeFem++ & - & - & - & - & - \\
\hline
\end{tabular}

\section{Geometries and Meshing}

Drawing programs used to generate geometries are usually specific programs with optimized graphics features that enable designers to use them quickly and intuitively, allowing various simple forms and complex geometries to be built and examined in a reasonably short time. These programs need to be able to exchange their output files with FreeFem++; this could be solved by means of exchange files. Besides the definition of geometries, another important part of the pre-process is meshing: the division of the continuous object into parts with limited dimensions (finite elements) and with nodes that contain the physical properties and interactions of the material with the actions. This meshing process should be carried out by a program that guarantees easy and correct execution.

\subsection{Salome Analysis}

Salome is an open source platform under the LGPL (Lesser General Public License) for the preand post-processing of numerical simulations. It enables geometries to be built in a user-friendly CAD environment that facilitates the construction of volumes in 3D and is quick and easy to learn. The program can be downloaded and information and support accessed from the official website [31]. The program promises speedy and intuitive pre-processing compatible with various calculation engines. It can mesh a given volume by considering different hypotheses and algorithms (hexahedron, tetrahedron, Netgen 1D-2D-3D, etc.). Submeshes can be created as well as groups and subgroups 
from these. The result is a 3D mesh that is seemingly accurate, but its usability is undermined by an excessively diffuse process for entering data. For the scientific user this probably leads to greater control over the process, but for the professional it is an impediment (Figure 2).

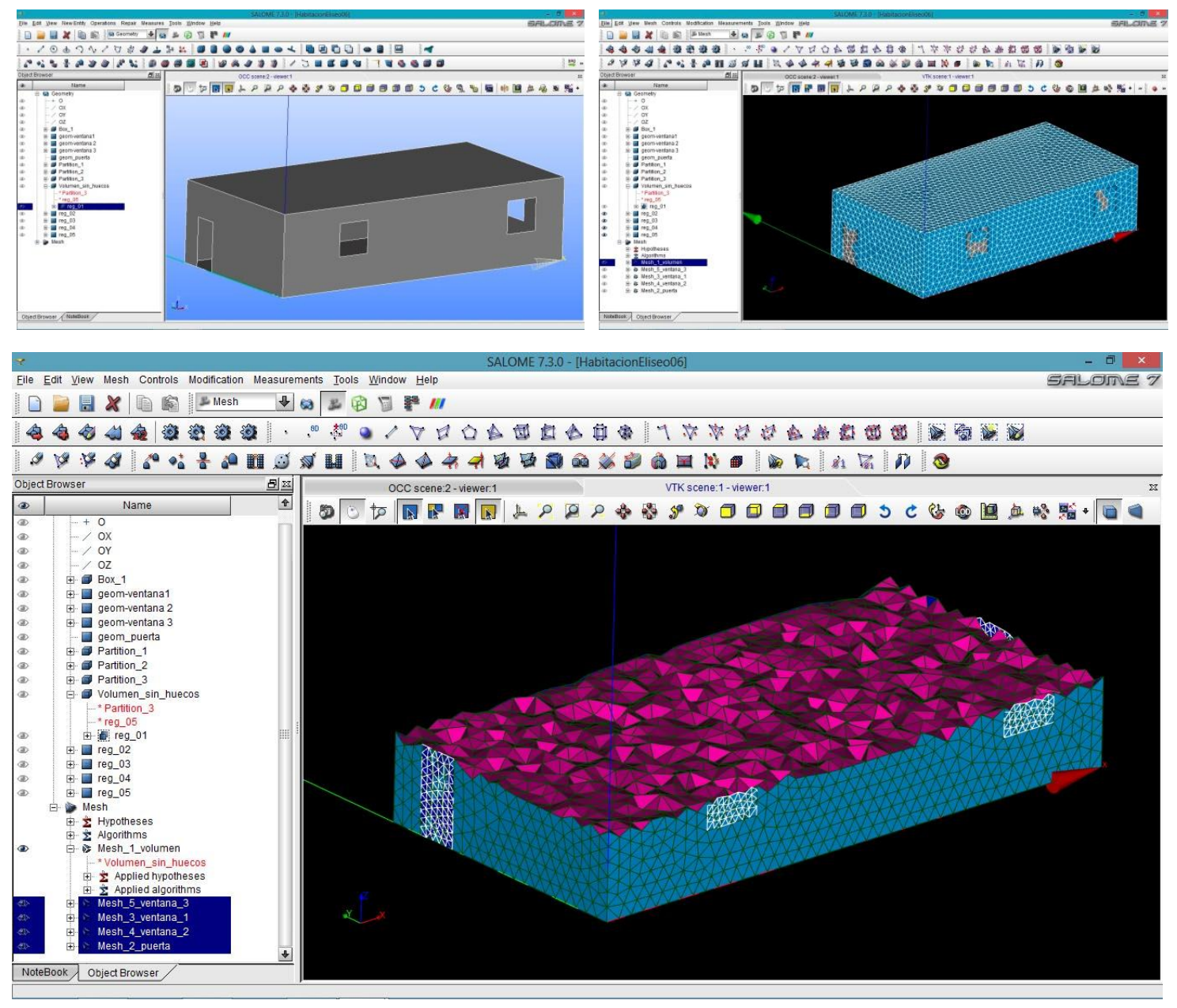

Figure 2. 3D geometries. An example from the current investigation.

Once the pre-processing is complete, we need to find a method for transferring the results to FreeFem++. The natural format of the Salome files has an *.hdf extension and those for the output files for the geometries can be *.brep, *.iges, *.igs, *.step, *.stp, *.stl, *.sat, or *.vtk. The meshing output formats have the following extensions: *.med, *.unv, ${ }^{*}$.stl, *.sauv, ${ }^{*}$.gmf, or ${ }^{*}$.dat. None of these meshing file formats can be imported directly to FreeFem++, but the geometries and meshes generated in Salome can be transferred indirectly to FreeFem++ by using the GMESH program as a bridge, as shown in Figure 3.

The first step is to export the file from Salome in a *.brep geometry format, which can be imported from GMESH [32]. GMESH also allows us to do the meshing, which can be saved in files with the *.mesh extension format. These file formats can be read by FreeFem ${ }^{*++}$, as explained later. We can also do the meshing in Salome, which requires exporting the mesh as a *unv file extension. This file format can be read by GMESH and from here, as in the previous case, saved as *.mesh, which can be read by FreeFem++. Moreover, GMESH may allow the user to generate 3D geometries in a CAD environment as well as the complete meshing of the volume, rendering it unnecessary to use Salome to carry out the same function. Salome has other inconveniences such as excessive size and demand on resources, and difficulties in the tag exporting process. Moreover, its usability is not as advanced as 
in the CAD programs designed specifically for drawing. Thus, the GMESH program was analyzed in greater detail to assess its viability as a tool to solve the problem proposed.
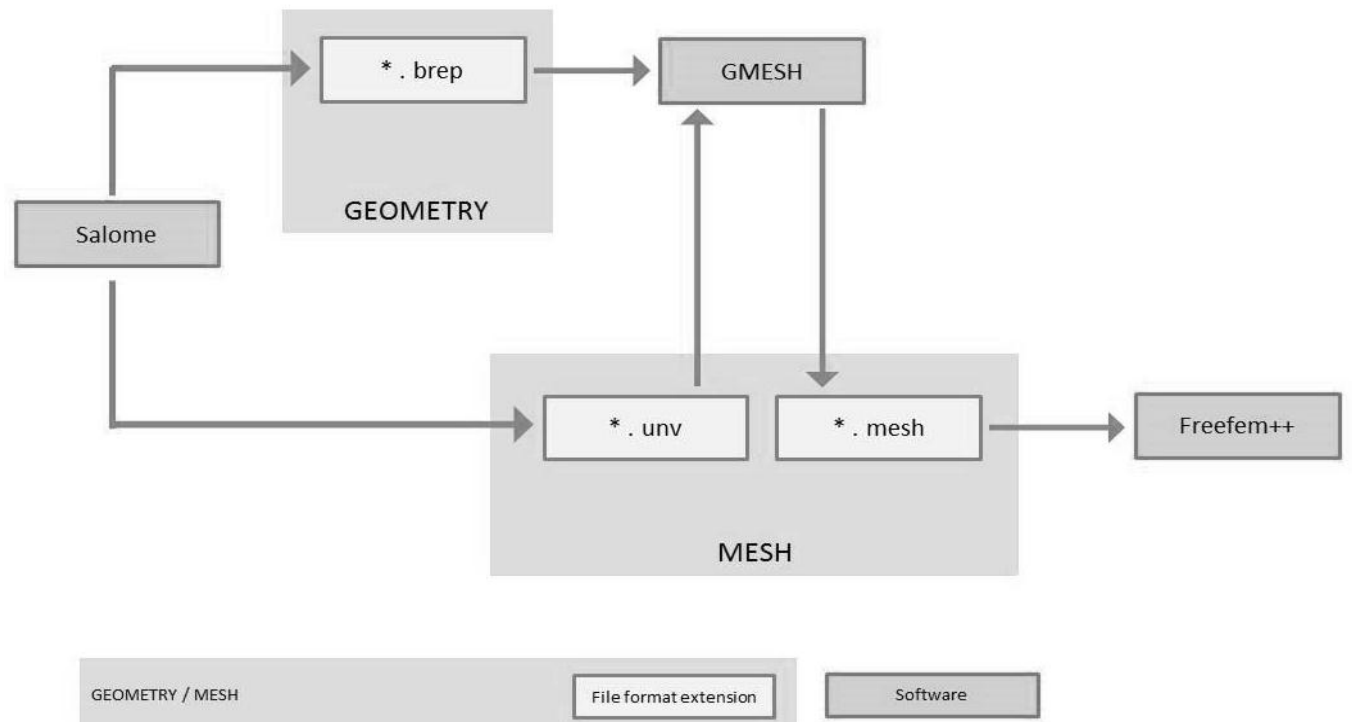

Figure 3. Diagram of the interaction between Salome and FreeFem++.

\subsection{GMESH Analysis}

The GMESH software has a strong meshing capacity that incorporates a calculation engine and pre- and post-processes [33]. It enables the user to erect geometries in a CAD environment, and its aim, according to the official website, is to provide a tool that is fast, light, and easy to use for meshing with inputs of parametric objects and advanced visualization capabilities. It allows its mesh to be exported in *.mesh, which can be read by FreeFem++. The GMESH and FreeFem++ integration is perfect, as the experiences of FreeFem++ community members demonstrate.

In the example shown in Figure 4a, meshing was done with Salome and exported using the *.unv format. Then, this file was imported into GMESH and the mesh was able to be opened without any problem (Figure 4). Then, the mesh was exported from GMESH as *.mesh (for example, "Room3d.mesh"). It is important not to confuse the *.mesh export file with the natural format saved by GMESH which is *.msh, as FreeFem++ cannot open this. It can be observed that FreeFem++ reads the mesh in *.mesh generated by Salome (Figure $4 b$ ).

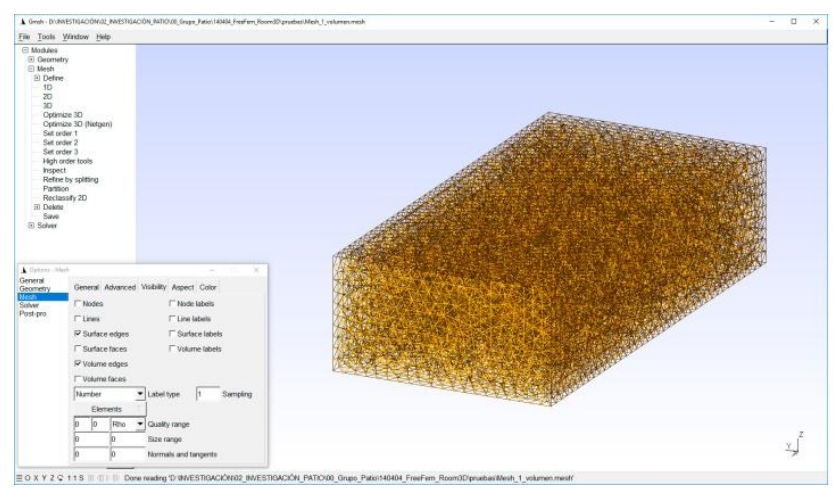

(a)

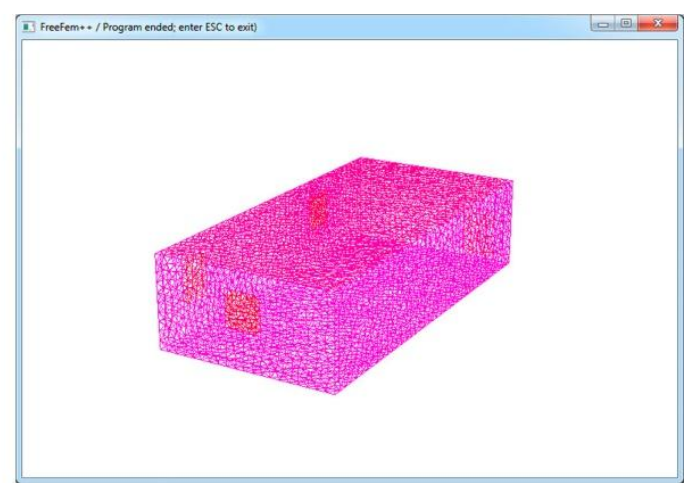

(b)

Figure 4. Mesh exported from GMESH to FreeFem++, (a) general mesh and (b) volume with windows. 


\section{Computer-Aided Design Programs}

The most efficient way to erect three-dimensional models for buildings is to use the drawing and 3D CAD programs most commonly applied in architecture. The two most widely used assisted drawing tools on the market for 3D constructions are AutoCAD ${ }^{\circledR}$ and SketchUp ${ }^{\circledR}$. AutoCAD is the main commercial CAD program for computer-assisted design but SketchUp is becoming the preferred program of use for quick and intuitive geometric $3 \mathrm{D}$ constructions as its basic version is free. Both are standard tools in architecture and engineering faculties.

\subsection{AutoCAD}

The Autodesk program is widely used in universities and architectural and engineering companies in many countries. Its official website offers ample information on the program's features and a downloadable test version [16]. Thanks to the utility of the IGES format, AutoCAD exports directly to IGES, although this option does not appear by default in the export dialogue box and you have to open particular submenus to find this option.

\subsection{SketchUp}

Although the AutoCAD program is the most popular, it has two major drawbacks that led us to search for possible alternatives. Despite the fact that the program is made specifically for CAD drawing, constructing three-dimensional volumes with this tool is not fast or intuitive. It is difficult to outline a volume and modify the finished geometry quickly. By contrast, AutoCAD offers considerable accuracy, and final projects are normally drawn up using this program.

However, the nature of the study in this investigation does not require mathematical precision. What is important is that the architectural spaces and their microclimate features are not affected by alterations in millimeters to their dimensions since the details of the architecture and the spaces are normally defined in centimeters. A meshing that generates a mesh of $10 \mathrm{~cm}$ to $30 \mathrm{~cm}$ is usually sufficient for the dimensional accuracy needed. What is more important is the speed at which 3D models can be constructed, an area in which AutoCAD is lacking. To solve the problem at the heart of this research requires constant experimentation with various geometries that can be quickly put together, thus enabling comparisons and decision-making on its formal design. Another drawback of AutoCAD is that this commercial program is quite expensive.

A good alternative is the much-used program for constructing 3D objects, SketchUp. It is simple and fast, the models can be easily modified, and the SketchUp Make basic version is free. Information about the program can be found on the official website, where it is also available for download [34]. Thus, the idea is to use SketchUp to build geometries quickly and simply and then export them in the IGES format, which GMESH can read, and continue the method proposed above. The SketchUp Make export options do not include exporting in IGES format, but the SketchUp community on the Internet has developed a plugin that enables this [35]. The "iges_export.rb" export file is copied into the Tools folder of SketchUp in the program files. The option to export the solid is found in the program tools' submenu under the name "IGES export".

\subsection{ParaView}

To improve the presentation and analysis of the results (post-processing), another program designed specifically for this task it is also considered: ParaView. This is an open source multiplatform tool for data analysis and visualization applications developed by the Los Alamos National Laboratory of the U.S. Department of Energy in collaboration with Kitware Inc. [36]. After performing the simulation calculation process in FreeFem++, the results can be exported from FreeFem++ to a VTK library (whose files have extension *.vtk) and read by ParaView, which provides the user with ample scope to analyze the data [37]. 


\section{Proposed Plug-In Procedure}

Based on what has been described so far, a specific tool for each part of the simulation (pre-process, process, and post-process) for the execution of this method is proposed. For constructing the geometry, the programs for drawing, design, and 3D construction most widely used among technicians, and for the meshing, GMESH. The pre-process is the building of the geometry and the meshing. For the process-the nucleus of the calculation of the numerical simulation via the finite element method for the study of microclimates [33] —we propose FreeFem++. For the post-process-in other words, the visualization and analysis of the results—-the ParaView program is suggested.

\subsection{File Exchange}

After studying the import and export compatibilities of the various programs, we propose to use the IGES format (whose files have extension *.igs) between the drawing programs and the GMESH meshing, and the MESH format (whose files have extension *.mesh) between GMESH and FreeFem++. IGES (Initial Graphics Exchange Specification) is a neutral data format that enables the digital exchange of information between computer-assisted design (CAD) systems. Despite the emergence of STEP, IGES continues to be the most widely used standard format for exchanging 3D graphics files.

In the proposed method, the geometry is drawn using AutoCAD ${ }^{\circledR}$ or SketchUp ${ }^{\circledR}$ and exported in the IGES format and read in GMESH. This program is used for meshing the volume generated as it is made specifically to carry out this task. The mesh is then exported as MESH. All this constitutes the pre-process. FreeFem++ reads the mesh format $\left({ }^{*}\right.$.mesh), and this program is then used to perform the calculations (process). The results are presented and analyzed (post-process) by exporting the results from FreeFem++ to a ${ }^{*}$.vtk library. These result files are read by the ParaView program where they can be easily studied and analyzed, and then exported to other data presentation formats (Figure 5).

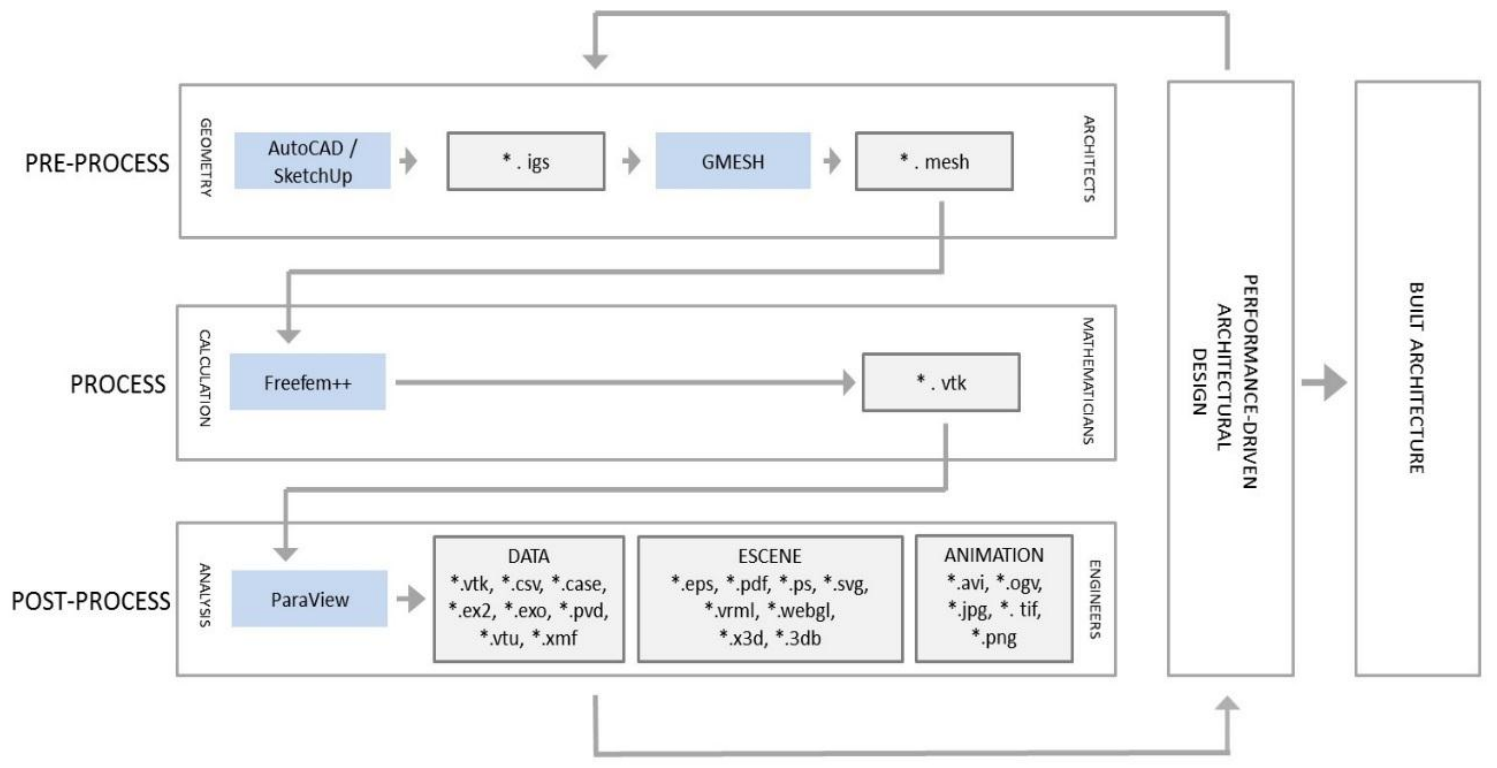

Figure 5. Diagram of the proposed plug-in method.

\subsection{Case Study}

An example of the proposed methodology's application can be used to illustrate the process by entering in Freefem++ a geometry and mesh of a courtyard $(10 \times 10 \times 10 \mathrm{~m})$ in a building $(30 \times 30 \times 10 \mathrm{~m})$ considering an air volume of $50 \times 50 \times 20 \mathrm{~m}$. The first step is to build the geometry in SketchUp.

In SketchUp Make, the "rectangle" tool is used to make a rectangle on the floor. On selecting the origin of the rectangle, it is possible to enter the boundary measurements that appear in the square 
in the bottom left corner directly, separated by full stops and commas, with speed and accuracy (Figure 6a).

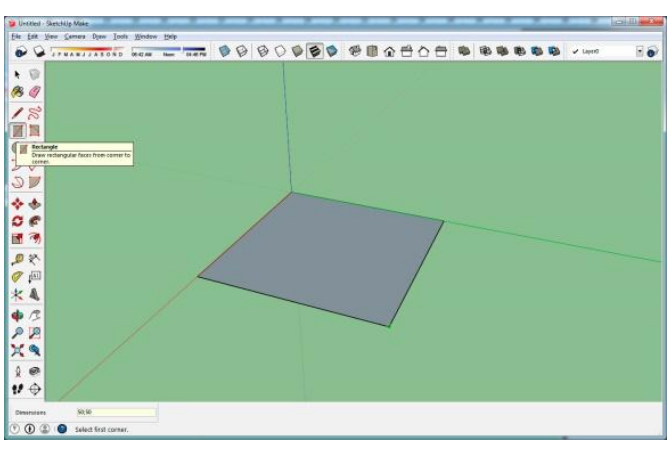

(a)

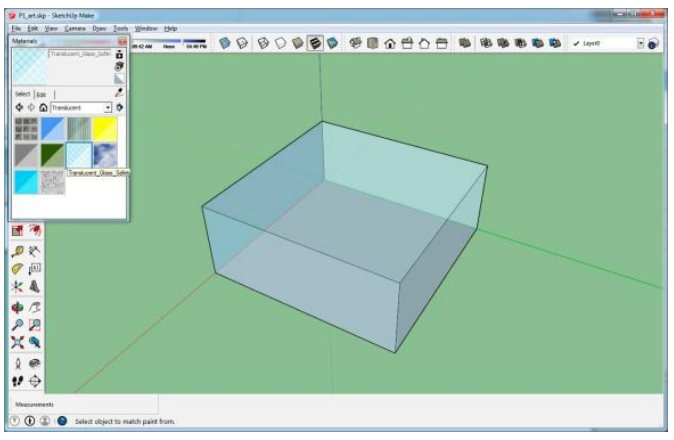

(c)

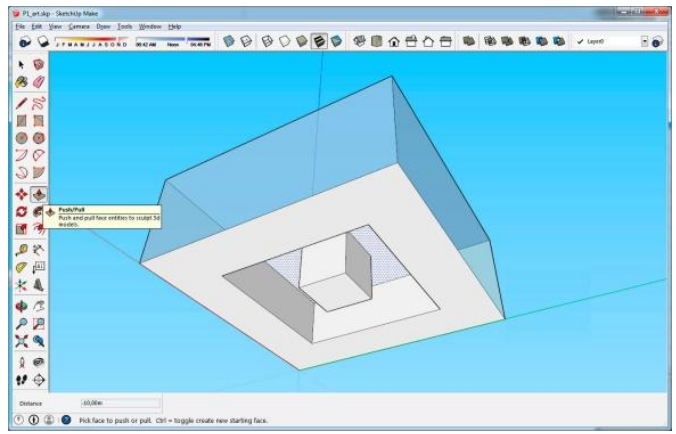

(e)

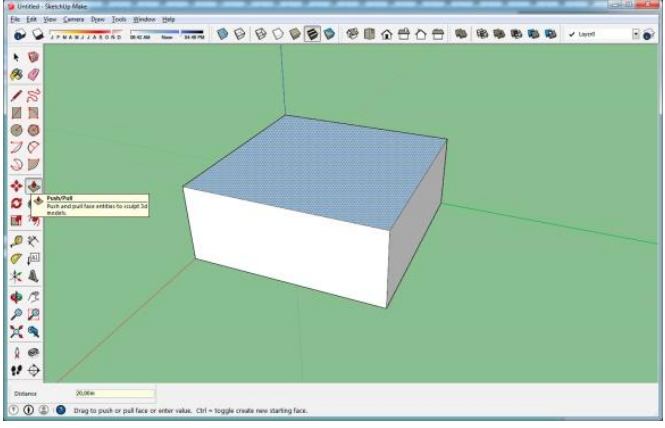

(b)

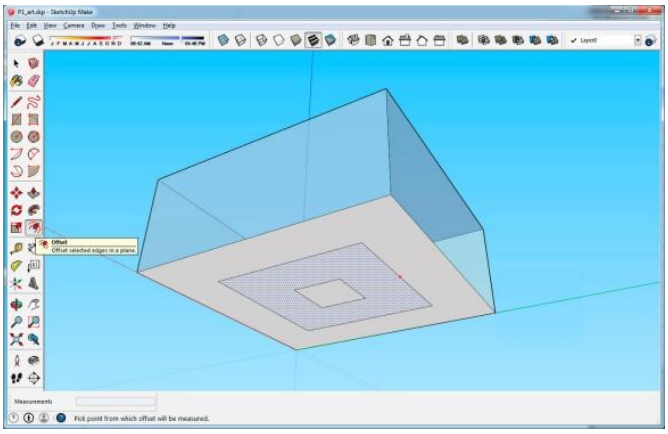

(d)

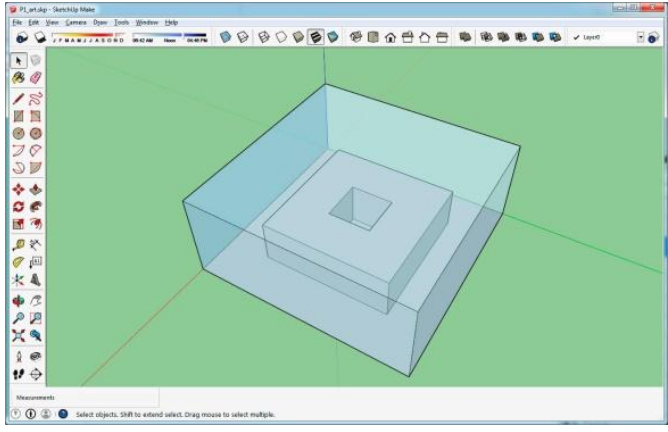

(f)

Figure 6. Case study geometry construction process in SketchUp, a to f process steps. (a): initial base dimension, (b): general volume, (c): internal volume, (d): 2D inner courtyard and surrounding exterior, (e): same in $3 \mathrm{D}$, (f): final shape with all its dimensional properties.

The push-pull tool is used to extrude the rectangle upwards, thus generating a volume. As in the previous case, the user can enter the precise numerical value of the movement when the side and the direction of the movement have been selected (Figure 6b).

This type of sketch is one of the simplest systems available for constructing volumes that allows trying out various forms with different thermodynamic behaviors. The volume can be modified at any time by stretching one of the sides with the push-pull tool; this is an example of the program's flexibility, enabling the volume to be modified quickly when searching for a form that generates a different microclimate.

Using the tools that enable operations between solids (intersecting, joining, subtracting, cutting, dividing), all of which are identified by icons at the top of the screen, complex parallelepiped geometries 
can be created with ease. Other tools allow us to create curved and complex non-parallelepiped geometries. The line or "offset tool" lets us draw reference lines on the side. The lines on a plane that delimit one area of a side of a solid in SketchUp define a region that is different from that plane. This feature can be identified by clicking on the zone and observing the shadowed area, and this can be cut or colored separately from the rest of the plane. This quality is very interesting because the program automatically identifies the region, labelling it so that it can then be recognized as a numerical model. The IGES format uses numbers to automatically identify each of the regions generated. Sometimes, assigning a color to these regions can give a better understanding of the geometry generated in SketchUp, thus avoiding errors of interpretation.

From this point, it is possible to export the geometry to IGES using the plugin placed in the tools menu (Figure 7a). When dealing with more complex geometries, we can check that only one group has been created in order to ensure that the exportation is done correctly. It is also important to remember that GMESH does not import files stored on lower levels (subfiles inside subfolders). It is advisable to temporarily shift the *.igs export files to the desktop to import them from GMESH without any problem.

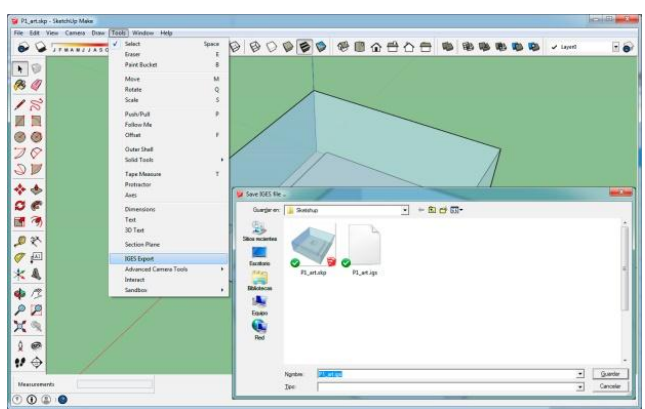

(a)

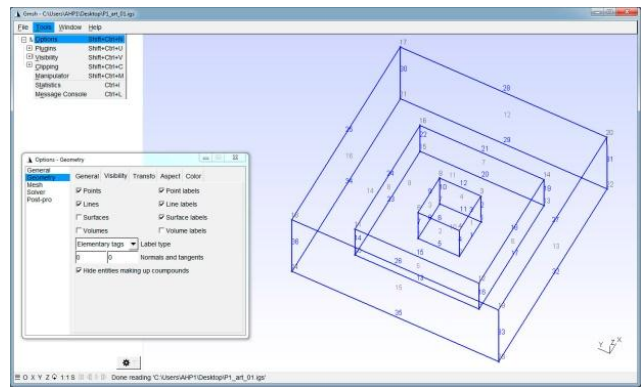

(c)

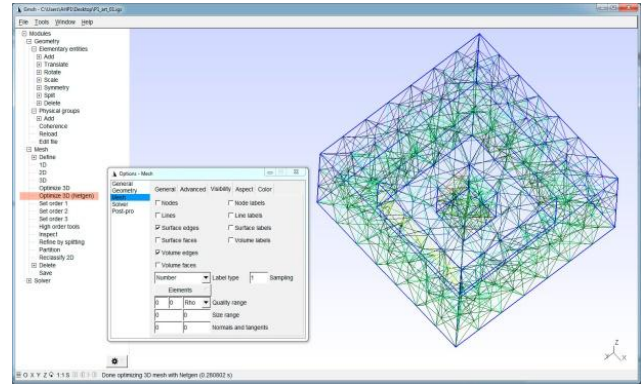

(e)

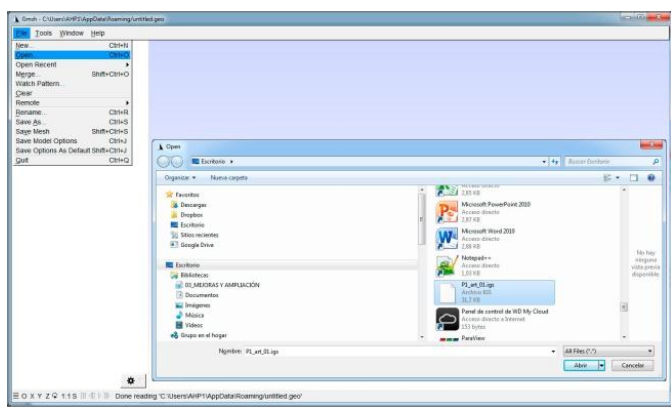

(b)

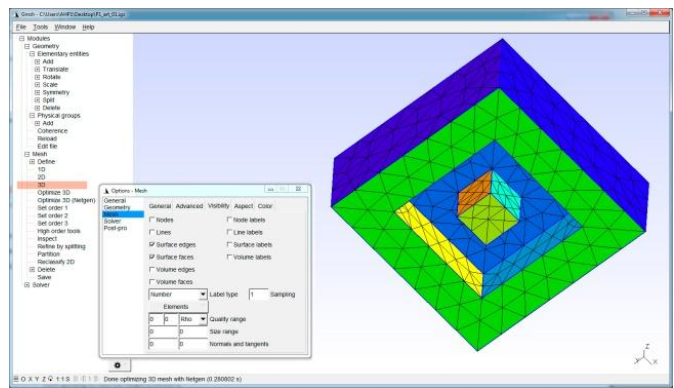

(d)

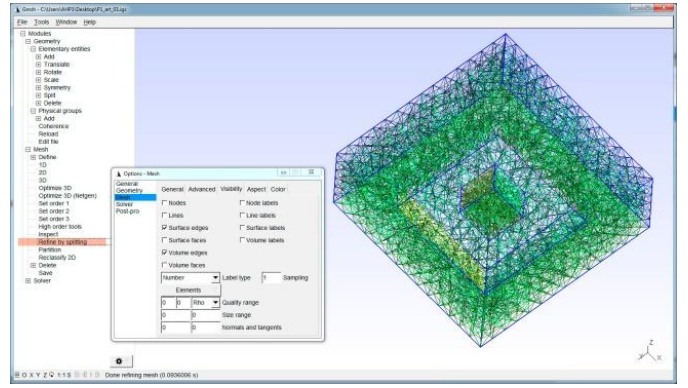

(f)

Figure 7. Exporting process of the case study geometry in the *.igs format from SketchUp, , a to $\mathrm{f}$ process steps. (a): object in SketchUp, (b): importing process, (c): object in GMESH, (d): initial mesh, (e): mesh densification, (f): final mesh. 
Then, the GMESH program is opened and the *igs file is imported. This is done by opening the File menu, selecting Open, and locating the *igs file on a level close to the desktop (Figure 7b). When the file is imported, nothing appears in the window. We need to open the "Tool" menu, select "Option", then "Geometry", and mark the elements required for visualization (Figure 7c). It is important to check that there are labels for the points (unmarked in the example), vertices, and differentiated sides and regions within the sides (the windows in the example). These labels are fundamental so that the regions can be identified and assigned different contours in FreeFem++. Now the 3D meshing can be done. This is done by opening the "Mesh" menu and clicking on 3D (in red in the figure). After that, the first meshing takes place. As in the previous case, the data which appear are confusing, with only the labels that correspond to the mesh nodes being visible. We again need to return to "Option" and select "Mesh" and mark the elements of the mesh we wish to see (Figure 7d). In "Mesh", it is important to be able to visualize the lines, the sides, and the vertices of the sides (2D mesh in sides) in order to check that the elements have different colors. We check that a 3D mesh has been done in the volume by selecting "Tool", "Option", "Mesh", and marking "Volume Edges" (Figure 7e). Now it is possible to proceed to optimizing and defining the mesh, first by clicking on "Optimize 3D (Netgen)", which is marked in red (Figure 7f). By clicking on it once, a slight repositioning of the mesh's tetrahedrons occurs. Another click produces the same effect, but this time it is less perceptible. If the clicking process is continued, it is possible to realize that the alterations become smaller and smaller until the mesh no longer changes. At this point, maximum optimization has been reached, thanks to the program's Netgen module.

If a tighter and more precise mesh is necessary, the "Refine by Splitting" option can be used. Unlike in the previous example, only a single click is normally necessary, as the mesh grows considerably in density (Figure 7f). A second click could make the mesh very dense, with too many polygons to enable calculation in FreeFem++ in a reasonable time. A third click would produce a mesh impossible to calculate. At this point we notice that GMESH has no option to "undo". If a wrong calculation is made in refining the mesh and it became too dense, it is possible to go back and start again by importing the *igs geometry.

To export the mesh for FreeFem++, select "File" and "Save As"; in the menu that appears with different import formats, *.mesh must be chosen (Figure 8a). It is important not to confuse this with the *.msh native format that GMESH uses to save the meshes by default. FreeFem++ cannot read the ${ }^{*}$.msh format, only *.mesh. Although the *.mesh format has been selected in the option menu, the file still has the *igs extension, so the new extension must be attached manually. The *.mesh folder created can be saved on any subdirectory level in the computer that can be read by FreeFem++. The mesh can be imported from FreeFem++ by writing the following lines of code:

$$
\begin{aligned}
& \text { mesh3 malla = readmesh3("P_1.mesh"); } \\
& \text { plot(malla); }
\end{aligned}
$$

This file is saved as *.edp, placing the mesh file "P_1.mesh" in the same directory as *.edp. When executing the edp, we observe that the mesh has been read by FreeFem++, as appears in Figure 8b [32]. In the processing or calculation phase, the air flow entering one window will be simulated in addition to the inner one. This is a typical laminar fluid mechanics problem where we apply the Navier-Stokes equation for a three-dimensional space:

$$
\left\{\begin{array}{c}
\frac{\partial u_{1}}{\partial t}+u_{1} \frac{\partial u_{1}}{\partial x}+u_{2} \frac{\partial u_{1}}{\partial y}-v \frac{\partial^{2} u_{1}}{\partial x^{2}}-v \frac{\partial^{2} u_{1}}{\partial y^{2}}+\frac{1}{\rho} \frac{\partial P}{\partial x}=0 \\
\frac{\partial u_{2}}{\partial t}+u_{1} \frac{\partial u_{2}}{\partial x}+u_{2} \frac{\partial u_{2}}{\partial y}-v \frac{\partial^{2} u_{2}}{\partial x^{2}}-v \frac{\partial^{2} u_{2}}{\partial y^{2}}+\frac{1}{\rho} \frac{\partial P}{\partial y}=-g \\
\frac{\partial u_{1}}{\partial x}+\frac{\partial u_{2}}{\partial y}=0
\end{array}\right.
$$

where:

the vector of the air velocity is $\vec{u}=\left(u_{1}, u_{2}\right)$;

$\mathrm{u}_{1}=\mathrm{u}_{1}(\mathrm{t}, \mathrm{x}, \mathrm{y}), \mathrm{u}_{2}=\mathrm{u}_{2}(\mathrm{t}, \mathrm{x}, \mathrm{y})$; 
the air pressure is $\mathrm{P}=\mathrm{P}(\mathrm{t}, \mathrm{x}, \mathrm{y})$;

the air density is $\rho$;

$\vartheta=\frac{\mu}{\rho}$ is the air kinematic viscosity;

$\mathrm{g}$ is the gravitational constant.

In the FreeFem++ code, the commands to read the mesh, the commands to solve these equations, and the commands to resolve and save each iteration in a *.vtk library are written as follows:

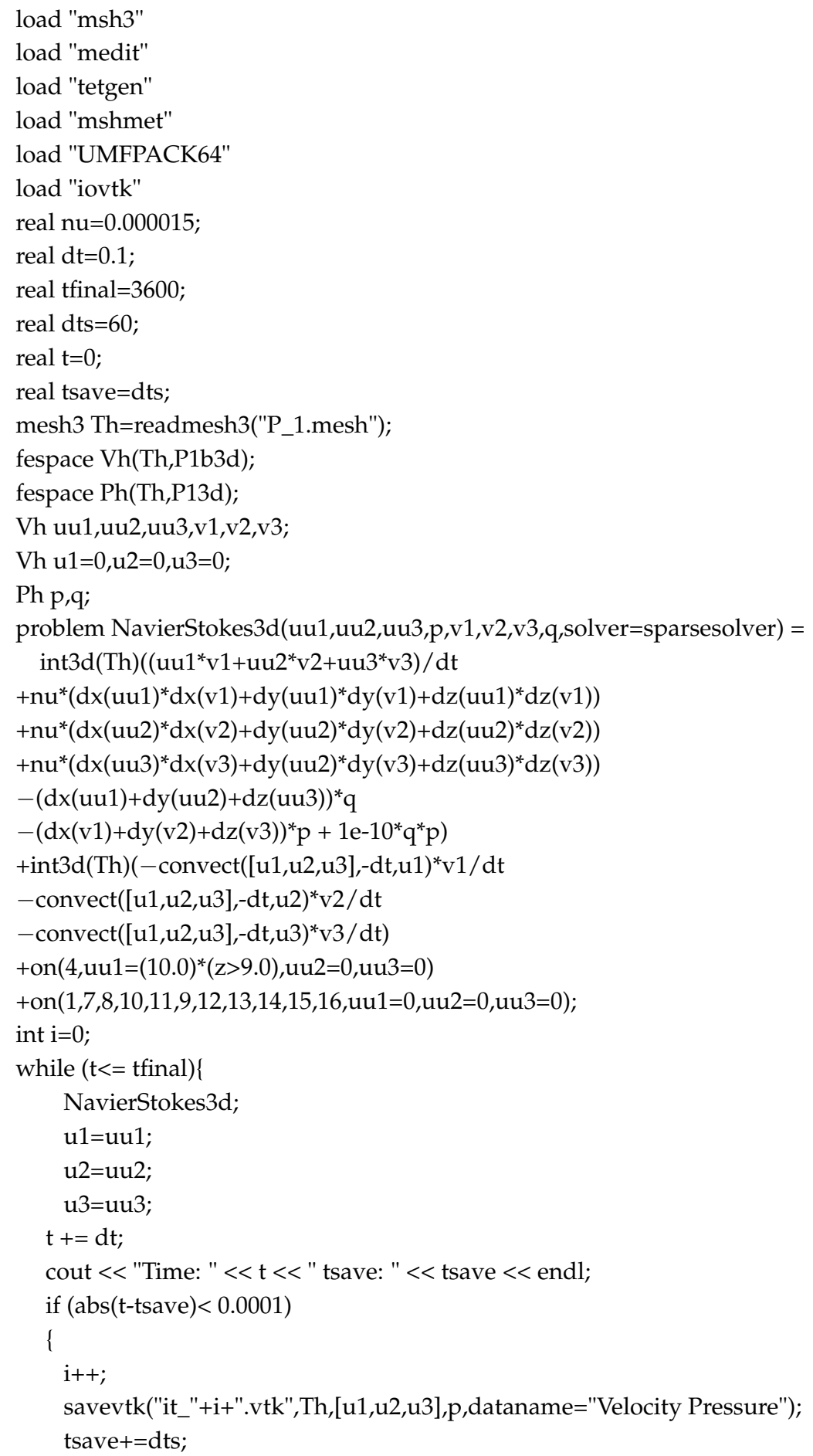




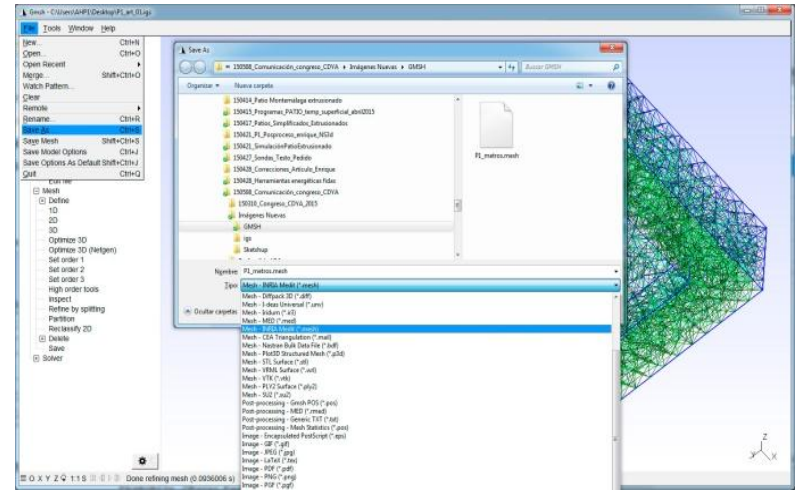

(a)

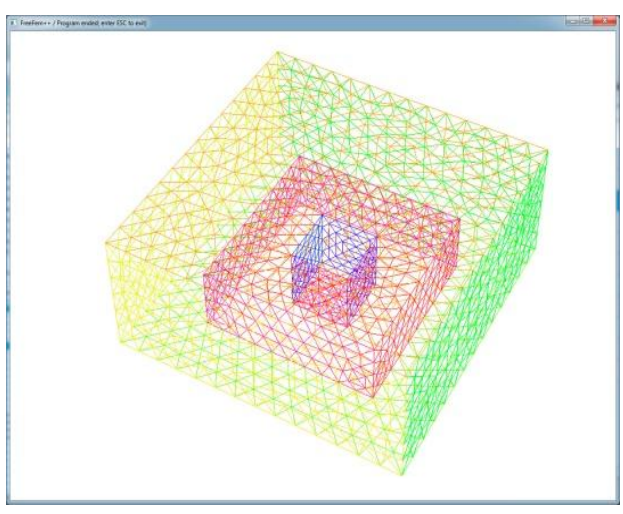

(b)

Figure 8. Mesh made in GMESH and imported in FreeFem++ with geometry constructed in SketchUp, a and b process steps. (a): importing process from GMESH, (b): result in FreeFem++

\subsection{Results}

The case study results presentation was done through open-source software ParaView. This software is not only able to read the results of FreeFem++ but also allows graphic data visualization, facilitating intuitive and almost immediate analysis. Results in Paraview, by means of a mesh made in GMESH and imported into FreeFem++ with geometry constructed in SketchUp, are shown in Figure 9. Figure 9a shows the example mesh in ParaView, and Figure 9b,c display the simulation results representing the vector field and stream lines, respectively. The influence of wind speed and direction on the generation of air flows in combination with the thermal impact of the facades determine the conformation of a vortex inside the courtyard and a thermal stratification in lower layers, as shown in Figure 9. The ParaView graphical interface allows a direct visualization of the geometry changes' influence on the courtyard thermal behaviour. Different colours represent different flow rates. Using the ParaView tool to open the *.vtk library, the program allows analysis of pressure values, speed vectors, and current lines, among other results of the simulation. It also helps us to visualize and understand its distribution and evolution within the three-dimensional space. This is vital for understanding the specific structures that emerge and which are the results of the interaction between the physical properties of the fluid in motion and the form of the space in which it moves. In other words, the design of the space modifies these structures. So, being able to see them more clearly enables us to produce an architectural design that best fits these characteristics.

The interplay between CAD and FreeFem++ and the subsequent visualization in ParaView allows us not only to apply a meshing system good enough for tackling problems involving thermodynamics and fluid mechanics, but to generate a decision-making design tool based on the data feedback through a suitable graphic support. This paper proposes a methodology based on open source software effective for adapting courtyard design to a specific climatic environment. The next step would be to create a unified platform that could integrate these steps into the one application. 


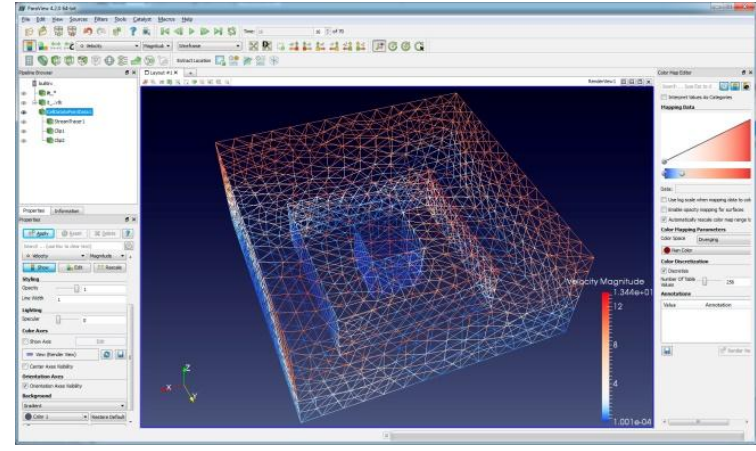

(a)

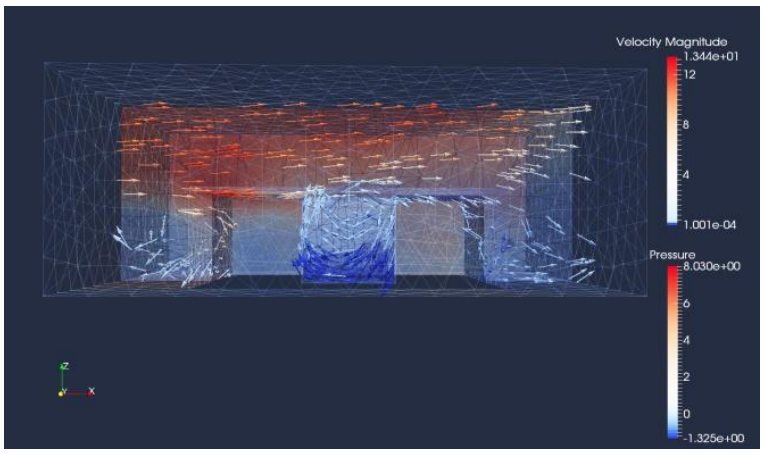

(b)

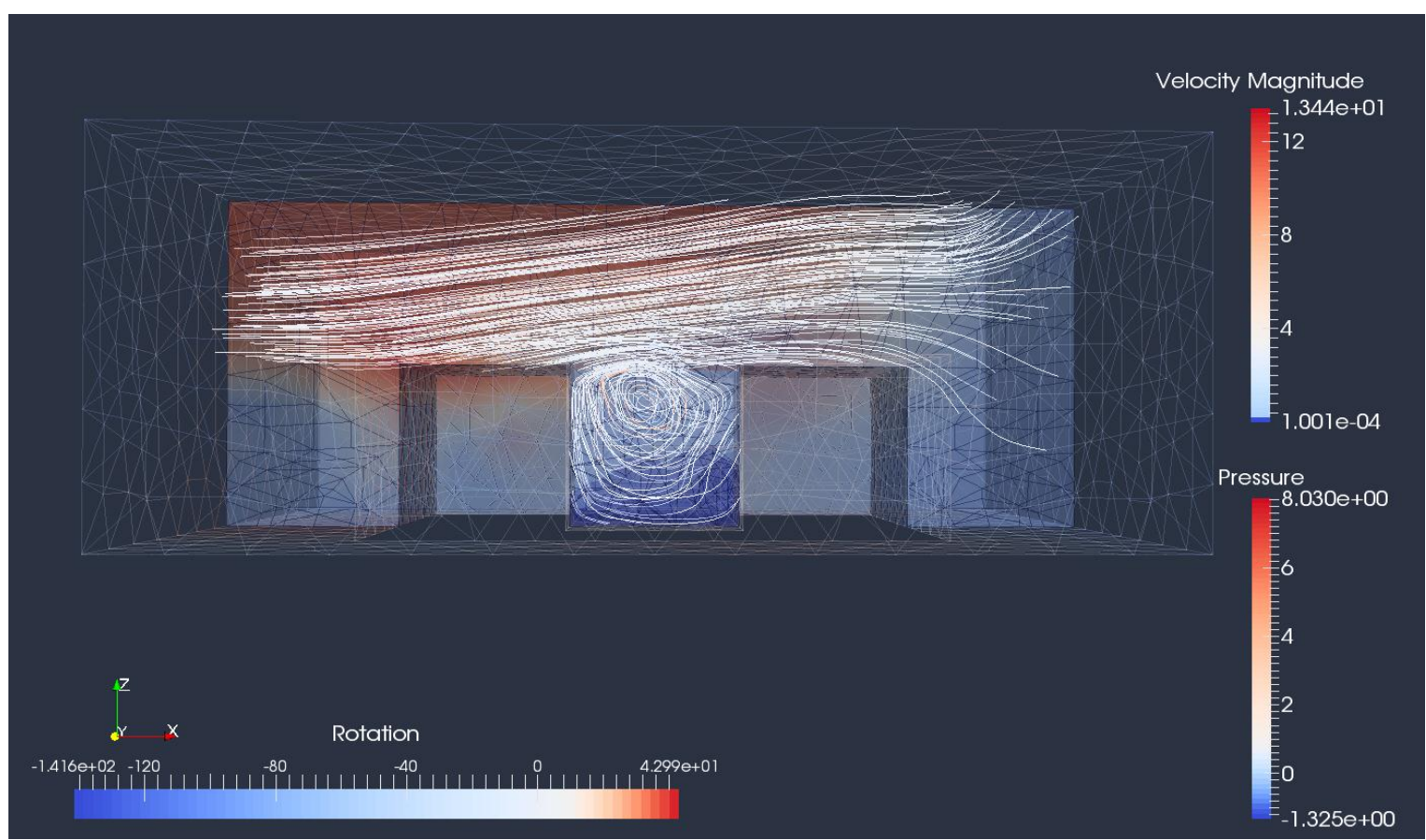

(c)

Figure 9. Results of the case study displayed by Paraview, a to c process steps. (a): general meshing view, (b) and (c): simulation results representing the vector field (b) and stream lines (c).

\section{Conclusions}

There is a huge opportunity regarding energy saving in the correct design of microclimates in outdoor spaces within courtyards in buildings or public spaces in cities. Nonetheless, increasing energy efficiency in buildings requires the development of simulation tools enabling us to gain a better understanding of these environments and perform more accurate calculations. The nature of the challenge means that different fields of knowledge, such as architectural design, mathematical models, and energy engineering, need to interact [38].

Programs widely in professional use, such as DesignBuilder, consider the air temperature in courtyards to be exactly the same as that outside, i.e., for these programs, a different microclimate in the courtyards does not exist. This has led to justification of recommendations and energy standards that advise limiting the shape factor (ratio between envelope and interior volume contained) in buildings.

Actual monitoring performed in courtyards by our research group and other authors has demonstrated that the temperature in a courtyard in summer is significantly lower than that outside, i.e., there is a microclimate within the same. The main aim of this study was to appraise the 
most commonly employed programmes for the energy simulation of buildings as a basis to bring forward a new methodology to achieve a more precise system that is also easy to implement within Computer-Aided Design software.

Despite the current availability of integrated programmes, such as emerging BIM systems, the aptitude showed by most common energy analysis simulation software packages for the modelling of thermal conditions in small-sized outdoor spaces such as inner courtyards is limited. Hence, its potential effectiveness not only depends on the amount of exchanged information, but also on a system configured in such a way that allows enough flexibility to predict the thermodynamical behaviour and the appropriate transparency to enable understanding of the mathematical model of the physical processes. These characteristics are more typical of open source codes.

Furthermore, there are some standardization challenges nowadays for energy performance assessment in a BIM context. The general framework must be a holistic or systemic approach which combines indoor climate requirements in a specific environment distinguishing transitional spaces' microclimates from the outdoor climate parameters with the required accuracy. Moreover, the widespread use of openBIM as a central technology would be desirable for information management that can combine inputs from different BIM, mostly free, open source software tools that enable full control over how the energy performance is calculated

The comparative study of the energy calculation tools included in Section 2 shows that the programme based on FreeFem++ possesses all these characteristics except for its current lack of compatibility with the main CAD design programmes used in architecture.

In this paper, a method connecting these drawing tools for generating geometries (AutoCAD and SketchUp) that enables them to be meshed (GMESH) and the calculations performed by FreeFem++ was developed. Also, a tool for data analysis was considered (ParaView).

The presented methodology sets the way forward for the development of a new unified tool that allows proper real-time knowledge of the architectural geometries influencing the generation of outdoor microclimates to improve both comfort and energy optimization.

A future step in the research will be to develop a method to calculate the temperatures produced by the microclimate of the courtyard and to subsequently introduce it into commercial energy balance programs, thus more accurately calculating the energy performance of buildings taking into account the energy savings produced by the courtyard.

Supplementary Materials: The following are available online at http:/ /www.mdpi.com/1996-1073/11/10/2665/s1, Video S1: 01_Preprocess_Simulation, S1: 02_Postprocess simulation.

Author Contributions: Conceptualization, J.R.-F. and E.D.F.-N.; Data curation, J.R.-F.; Formal analysis, C.R.-G.; Funding acquisition, C.G.-M.; Investigation, J.R.-F., C.G.-M. and C.R.-G.; Methodology, J.R.-F. and E.D.F.-N.; Project administration, C.G.-M.; Software, J.R.-F. and E.D.F.z-N.; Supervision, C.G.-M.; Writing-original draft, J.R.-F.; Writing-review \& editing, C.G.-M. and C.R.-G.

Funding: This work was supported by the National Government of Spain Research Project MTM2015-64577-C2-2-R.

Acknowledgments: The authors wish to acknowledge the IUACC "Instituto Universitario de Arquitectura y Ciencias de la Construcción" for the necessary support to develop this research.

Conflicts of Interest: The authors declare no conflict of interest. The founding sponsors had no role in the design of the study; in the collection, analyses, or interpretation of data; in the writing of the manuscript, and in the decision to publish the results.

\section{References}

1. Fernandez-Nieto, E.D.; Lucas, C.; de Luna, T.M.; Cordier, S. On the influence of the thickness of the sediment moving layer in the definition of the bedload transport formula in Exner systems. Comput. Fluids 2014, 91, 87-106. [CrossRef]

2. De La Flor, F.S.; Dominguez, S.A. Modelling microclimate in urban environments and assessing its influence on the performance of surrounding buildings. Energy Build. 2004, 36, 403-413. [CrossRef]

3. Alvarez, S. Experimental work and analysis of confined urban spaces. Sol. Energy 2001, 70, $263-273$. 
4. Rojas, J.M.; Galán-Marín, C.; Fernández-Nieto, E.D. Parametric study of thermodynamics in the mediterranean courtyard as a tool for the design of eco-efficient buildings. Energies 2012, 5, 2381-2403. [CrossRef]

5. Shi, X.; Yang, W. Performance-driven architectural design and optimization technique from a perspective of architects. Autom. Constr. 2013, 32, 125-135.

6. Yi, Y.K.; Malkawi, A.M. Optimizing building form for energy performance based on hierarchical geometry relation. Autom. Constr. 2009, 18, 825-833. [CrossRef]

7. Rojas-Fernández, J.M.; Domínguez-Hernández, L. Corporate Web of Arquitectos Hombre de Piedra. Available online: https:/ /hombredepiedra.com/en/research/mediterranean-courtyard/ (accessed on 2 July 2018).

8. Abanda, F.H.; Vidalakis, C.; Oti, A.H.; Tah, J.H. A critical analysis of Building Information Modelling systems used in construction projects. Adv. Eng. Softw. 2015, 90, 183-201. [CrossRef]

9. Mansuri, D.; Chakraborty, D.; Elzarka, H.; Deshpande, A.; Gronseth, T. Building Information Modeling enabled Cascading Formwork Management Tool. Autom. Constr. 2017, 83, 259-272. [CrossRef]

10. Pärn, E.A.; Edwards, D.J. Conceptualising the FinDD API plug-in: A study of BIM-FM integration. Autom. Constr. 2017, 80, 11-21. [CrossRef]

11. NBS. Building Information Modelling Report. 2016. Available online: http://www.thenbs.com/pdfs/NBSNational-BIM-Report-2016.pdf (accessed on 2 July 2018).

12. López-Cabeza, V.P.; Galán-Marín, C.; Rivera-Gómez, C.; Roa-Fernández, J. Courtyard microclimate ENVI-met outputs deviation from the experimental data. Build. Environ. 2018, 144, 129-141. [CrossRef]

13. Ramírez-Balas, C.; Fernández-Nieto, E.; Narbona-Reina, G.; Sendra, J.; Suárez, R. Thermal 3D CFD Simulation with Active Transparent Façade in Buildings. Energies 2018, 11, 2265. [CrossRef]

14. Official Web of ANSYS Fluent. Available online: https://www.ansys.com/es-es/products/fluids/ansysfluent (accessed on 2 July 2018).

15. Official Web of DesignBuilder. Available online: http:/ / www.designbuilder.co.uk/ (accessed on 2 July 2018).

16. Official Web of Autodesk Ecotec Analysis. Available online: http:/ / usa.autodesk.com/ecotect-analysis / (accessed on 2 July 2018).

17. Chronis, A.; Liapi, K.A.; Sibetheros, I. A parametric approach to the bioclimatic design of large scale projects: The case of a student housing complex. Autom. Constr. 2012, 22, 24-35. [CrossRef]

18. Robinson, D.; Campbell, N.; Gaiser, W.; Kabel, K.; Le-Mouel, A.; Morel, N.; Stone, A. SUNtool-A new modelling paradigm for simulating and optimising urban sustainability. Sol. Energy 2007, 81, 1196-1211. [CrossRef]

19. Idczak, M.; Groleau, D.; Mestayer, P.; Rosant, J.M.; Sini, J.F. An application of the thermo-radiative model SOLENE for the evaluation of street canyon energy balance. Build. Environ. 2010, 45, 1262-1275. [CrossRef]

20. Matzarakis, A.; Rutz, F.; Mayer, H. Modelling radiation fluxes in simple and complex environments: Basics of the RayMan model. Int. J. Biometeorol. 2010, 54, 131-139. [CrossRef] [PubMed]

21. Tumini, I.; Higueras-García, E. Strengths and weaknesses of urban microclimate simulation tools. DYNA Energía Sostenibilidad 2013, 1, 1-17.

22. Official Web of EnergyPlus. Available online: http://apps1.eere.energy.gov/buildings/energyplus/ (accessed on 2nd July 2018).

23. Official Web of ENVI-Met. Available online: http:/ / www.envi-met.com/ (accessed on 2 July 2018).

24. Yang, X.; Zhao, L.; Bruse, M.; Meng, Q. Evaluation of a microclimate model for predicting the thermal behavior of different ground surfaces. Build. Environ. 2013, 60, 93-104. [CrossRef]

25. Yang, X.; Zhao, L.; Bruse, M.; Meng, Q. An integrated simulation method for building energy performance assessment in urban environments. Energy Build. 2012, 54, 243-251. [CrossRef]

26. Official Web of Freefem++. Available online: http:/ / www.freefem.org/ (accessed on 2 July 2018).

27. Fernández, F.J.; Alvarez-Vázquez, L.J.; Martínez, A.; Vázquez-Méndez, M.E. A 3D optimal control problem related to the urban heat islands. J. Math. Anal. Appl. 2017, 446, 1571-1605. [CrossRef]

28. Ramírez-Balas, C.; Fernández-Nieto, E.D.; Narbona-Reina, G.; Sendra, J.J.; Suárez, R. Numerical simulation of the temperature evolution in a room with a mur neutralisant. Application to "The City of Refuge" by Le Corbusiero. Energy Build. 2015, 86, 708-722. [CrossRef]

29. Bernard Barrois, Example of Use of Freefem ++ for an Object 3D. Web on Freefem ++ Inside the Official Web of the Univerisad of Murcia. Available online: http:/ / www.um.es/freefem/ff++/pmwiki.php?n=Main. Room3D (accessed on 2 July 2018). 
30. Zhang, R.; Zhang, Y.; Lam, K.P.; Archer, D.H. A prototype mesh generation tool for CFD simulations in architecture domain. Build. Environ 2010, 45, 2253-2262. [CrossRef]

31. Official Web of Salome Software. Available online: http:/ / www.salome-platform.org/ (accessed on 2 July 2018).

32. Official Web of GMESH. Available online: http:/ /geuz.org/gmsh/ (accessed on 2 July 2018).

33. Almhafdy, A.; Ibrahim, N.; Ahmad, S.S.; Yahya, J. Courtyard Design Variants and Microclimate Performance. Procedia-Soc. Behav. Sci. 2013, 101, 170-180. [CrossRef]

34. Official Web of Sketchup. Available online: http:/ / www.sketchup.com/ (accessed on 2 July 2018).

35. Exports the Model to IGES Format. Available online: http://rhin.crai.archi.fr/rld/download.php?file=iges_ export_V0.6.zip (accessed on 2 July 2018).

36. Official Web of ParaView. Available online: http:/ / www.paraview.org/ (accessed on 2 July 2018).

37. Save in vtk File from Freefem++ and Read from ParaView. Inside the Official Web of Universidad de Murcia. Available online: http://www.um.es/freefem/ff++/uploads/Main/paraview_freefem_english.pdf (accessed on 2 July 2018).

38. Geyer, P.; Stopper, J.; Lang, W.; Thumfart, M. A Systems Engineering Methodology for Designing and Planning the Built Environment-Results from the Urban Research Laboratory Nuremberg and Their Integration in Education. Systems 2014, 2, 137-158. [CrossRef]

(c) 2018 by the authors. Licensee MDPI, Basel, Switzerland. This article is an open access article distributed under the terms and conditions of the Creative Commons Attribution (CC BY) license (http://creativecommons.org/licenses/by/4.0/). 